\title{
COVIDifying Education through the Lens of Award-Winning Educators in a State University in the Philippines
}

Joseph B. Quinto

Benguet State University, Benguet, Philippines

ARTICLE INFO

Keywords:

Distance Education

Pedagogical Practices

Teaching Experiences

Award-Winning Educators

\begin{abstract}
Paradigm shifts in the field of education have been an issue in the Philippines since the COVID-19 pandemic struck. To fill this gap, this study sought to highlight the pedagogical practices and teaching experiences of award-winning educators in a State University. The qualitative data extracted from semi-structured interviews were analyzed following a thematic analysis based on descriptive phenomenology. One finding revealed that the educators' years in service and educational attainments were helpful in their migration from face-to-face to distance education, even though the number of course preparations was a weight on their shoulders. Secondly, the educators conducted their classes through preparation and implementation via fifteen instructional methods, formative and summative assessments, and feedback. On another note, the educators determined six roadblocks in their teaching practice with explanations on how they overcame them. Amidst all these, they mentioned that it is imperative to uphold empathy in the conduct of their classes.
\end{abstract}

\section{Introduction}

Countries across the globe have experienced a paradigm shift due to the COVID-19 pandemic, and this includes the education sector. One of the most significant shifts is in the way education is delivered, from the traditional on-site or residential to online platforms (Panev, 2021). Due to unanticipated requests for formerly face-to-face courses to be taught online, the routine operation of schools has been hampered, as has the obstruction of face-to-face sessions, creating special problems (Jose Sa \& Serpa, 2020; Rapanta et al., 2020). Alternative learning systems have been adopted by various countries to respond to these educational dilemma (Rasmitadila et al., 2020). Stanistreet et al. (2021b) observed that education systems shifted the center of the teaching/learning process from schools to home contexts, aided by technology and the active participation of parents and guardians to help students avoid obstacles caused by school closures (Morgan, 2020).

But the abrupt transition to distance education has also exposed and compounded existing educational disparities (Stanistreet, et al., 2021a). Dhawan (2020) highlighted those educational institutions that were not into shifting to online teaching were left with no choice. Commenting on new online educational practices, Tartavulea et al. (2020) opined those teachers now distribute materials and employ internet and video conferencing in the teachinglearning process, which differed from past pedagogical techniques.

\footnotetext{
${ }^{*}$ Corresponding author E-mail address: j.quinto@bsu.edu.ph 
Educational practices have been adopted by schools, teachers, and students to adjust to the new normal in education, although these alternative learning systems seem to pose various challenges. It was found in the research of Alawamleh et al. (2020) that learners preferred faceto-face classes to online classes for reasons such as lack of motivation, understanding of the material, decrease in communication levels between the students and their instructors, and their feeling of isolation caused by online classes. To aid this, the significance of employing multiple online resources to present to students and engaging them with different virtual lessons is essential (George, 2020; Shenoy et al., 2020). Instructors may also cope with digital inequity by putting in more effort and changing their perspectives, according to the study of Williams et al. (2021). To add, asynchronous learning, which works best in digital media, should be used by schools and universities to increase their capacity to teach remotely (Daniel, 2020).

Teachers noted in the research of Jackson et al. (2021) that their preparations for dealing with the requirements of different learners online are inadequate, prompting them to seek more training in this area. Nonetheless, professors in the research of Zamora-Antuñano et al. (2021) took on the task of preparing for emergency remote teaching and training using a new technology platform. Furthermore, professional development focused both on curriculum design and the use of instructional technology at both university and school levels should be supported (Cunnigham, 2021; Stevens, 2020). Daniel (2020) expressed that institutions, instructors and students will continue to seek flexible solutions to the disruptions to learning trajectories created by COVID-19. This effect, however, may not remain unless instructors are encouraged to continue to grow and learn (Spoel et al., 2020).

\section{Literature Review}

\subsection{Distance Education}

Distance education, or Open and Distance Learning as it is currently known, stretches back to the 1800 s. It was once seen as a fringe type of education in comparison to traditional campusbased education has grown in popularity and use in the twenty-first century (Saykili, 2018). Moreover, it is a teaching paradigm in which students and teachers are not in the same physical location; it is a teaching model in which students and teachers are taught in online settings using technological products (Gökbulut, 2020), provided by numerous institutions across the world to individuals with varying degrees of preparation in order to achieve diverse goals and purposes (Bertiz \& Karoğlu, 2020). According to Kapur (2019), the curriculum is carried out using specifically produced resources, also known as self-study materials, which are provided to students via a variety of media, including print, television, radio, satellite, audio and video cassettes, CD-ROMs, the internet, the World Wide Web, and so on. Arain and Munshi (2019) surmised that it provides education facilities at the doorsteps and is designed especially for the people at home and job or far from the educational facility. Individual learning is strongly linked to the student's own features and qualities, as well as their personal responsibility and drive, in distance education (Sharonova \& Avdeeva, 2020).

\subsection{Flexible Learning}

Flexible learning is defined as a pedagogical method that allows for flexibility in terms of time, location, and audience with a concentration on the use of technology, but not exclusively. Although it frequently employs distance education delivery techniques and educational technology facilities, this may vary based on technological levels, device availability, internet access, digital literacy level, and approaches (CHED Memorandum Order No.4, s. 2020). Gayon and Tan (2021) stated that learners may choose where, when, and how they learn with flexible learning. Teachers are tasked with balancing the distinct demands of residential and distance learning in terms of speed, location, method, and learning outcomes. Concerning this, 
institutions have adopted flexible learning as a way of learning for the new normal of education, notably online and modular learning (Cascayan, et al., 2021).

Despite being geographically remote during teaching, online distance learning uses the teacher as a facilitator, encouraging active participation of learners through the use of various internetbased technologies. The internet is utilized to facilitate student-teacher and peer-to-peer communication (Tadeo, 2021). Meanwhile, a module is a self-contained unit of teaching designed to meet certain instructional goals. It is self-directing in that it contains directions on how to do various investigations as well as a list of materials and other resources that should be used in conjunction with the module's content (Trovela, 2021).

Much research has already been carried out on the paradigm shifts in the context of education in these trying times. However, debate still continues about the pedagogical practices in the Philippines as face-to-face classes will not push through for the majority of degree programs in higher educational institutions in Academic Year, 2021-2022. Henceforth, this research aimed to spotlight the pedagogical practices and teaching experiences of award-winning educators in a State University in the Philippines during the COVID-19 pandemic. Specifically, it sought to answer the following research queries:

RQ1: How did the profiles of the award-winning educators affect their migration from face-toface to distance education?

RQ2: How did the award-winning educators conduct their classes in the wake of the pandemic?

RQ3: What were the roadblocks that the award-winning educators encountered in their classes and how did they overcome them?

\section{Materials and Methods}

\subsection{Research Design}

The study followed a qualitative-phenomenological research design. This focused on the educators' lived experiences, and how they had both subjective and objective experiences of teaching during the COVID-19 pandemic (Creswell \& Poth, 2018).

\subsection{Site and Participants}

The research was conducted in one State University in the Philippines. The sample was chosen based on the search made by the university's Supreme Student Government (SSG) on the students' choice for the most adaptive, effective, and flexible teachers amidst the new normal in education in the first semester of Academic Year, 2020-2021. From 31 nominees, 10 educators were awarded. However, 2 out of the 10 awardees declined to participate in the study.

\subsection{Instrumentation}

To address the research queries at hand, the researcher created an interview guide that followed the framework for the development of a qualitative semi- structured interview guide by Kallio, Pietila, Johson, and Kangasniemi (2016). The phases included identifying the prerequisites for using semi-structured interviews, retrieving and using previous knowledge, formulating the preliminary semi-structured interview guide, pilot testing the guide, and presenting the complete semi-structured interview guide. After the formulation of the preliminary semi-structured interview guide, it underwent an expert validity via an instructor with a doctorate degree. Then, two nominees from the roster were selected for the pilot testing. Based on the results, the researcher incorporated some changes in the interview guide. 


\subsection{Data Gathering Procedure}

The researcher sent modified consent letters adopted from the book of Ravitch and Carl (2016) and the interview guide to the awardees through Facebook Messenger. After their confirmation, the researcher asked their most convenient time and their preferred platforms for the interview. The participants all agreed to conduct it face-to-face following minimum health protocols. A one-on-one in-depth interview was done because the research involved obtaining a sense of how the educators viewed their situations and what their experiences had been around the research topic under consideration according to Morris (2015). The interviews had an average span of 39 minutes. When the data was transcribed, they were sent back to the participants for member check or participant validation in order to verify the accuracy of statements and/or transcripts (Ravitch \& Carl, 2016). The remarks of the participants were, then, taken into consideration.

\subsection{Data Analysis}

The data was analyzed following a qualitative thematic analysis based on descriptive phenomenology by Sundler, Lindberg, Nilsson, and Palmer (2019). The process of analysis included an achievement of familiarity with the data through open-minded reading, search for meanings and themes, and organization of themes into a meaningful wholeness.

\section{Findings and Discussion}

\subsection{Research Question 1}

Table 1 shows the award-winning-educators' number of years in the teaching profession, their highest educational attainments, and their number of course preparations per semester during the pandemic.

Table 1.

Profiles of the Educators

\begin{tabular}{cccc}
\hline Educators & Years in Service & Educational Attainment & $\begin{array}{c}\text { Course Preparations per } \\
\text { Semester }\end{array}$ \\
\hline E1 & 4 & Master of Science & $5-7$ \\
E2 & 5 & Master of Arts in progress, Juris Doctor & 4 \\
E3 & 34 & Doctor of Education & 3 \\
E4 & 4 & Master of Arts & $2-4$ \\
E5 & 12 & Master of Science & $3-4$ \\
E6 & 21 & Doctor of Philosophy & 5 \\
E7 & 24 & Doctor of Philosophy & $3-4$ \\
E8 & 11 & Doctor of Philosophy & $3-4$ \\
\hline
\end{tabular}

All the educators agreed that their years in service and their educational attainments helped them in their migration from face-to-face to distance education in varying degrees. The educators stated that their years in service helped them whereby their responses are enumerated below:

"E3: Yes, experience is a great factor. Secondary is the educational attainment, although it still contributes a lot on how you're able to adjust to new learnings as far as teaching is concerned."

"E7: Of course, because you know how to identify the essential outcomes. Next, there is the topic that you discuss and the overall management of the class. I think it's easier to identify how you will do it, how you will say it, and how you can remedy things so that you can finish it right away. Unlike when you are a beginner, maybe you will need to do 
it from A-Z. If you're a little used to it through experience, you can combine A-J all at once."

"E8: Surely, my teaching experience and my educational attainments have helped me in my migration from face-to-face to distance education. My teaching experience specifically taught me how to adjust to our tough situation more easily, while my educational attainment helped me in researching for viable materials and resources that I could possibly use. In addition, the databases that I have been familiar with during my graduate school are exactly the same databases I use in researching. I found better enlightenment on how distance education works, the challenges, and how to counteract them."

In general, workers develop knowledge, skills, and productivity as a result of their experience. (Rice, 2013). Also, teachers with many years of experience in teaching are effective in the use of direct instructional techniques (Nikolaros, 2014). However, the results in the study of Irvine (2019) show that the connection between total years of experience and teacher effectiveness, as assessed by student performance increases, is complicated, subtle, and nonlinear. Still, the award-winning educators clearly stated that their years in service helped them in their migration from face-to-face to distance education. In terms of educational attainments, studies suggest that instructors with postgraduate degrees have a deeper understanding and dedication to the profession, allowing them to change curricular goals and better prepare pupils to succeed in school (Klett, 2018). Moreover, graduate school allows a person to become an expert in their area (Harrison, 2013). All of these research studies are consistent with the responses of the award-winning educators.

What is more is that some educators found assistance in other means like from family members and surfing the internet. For example, E1 stated that "I think what influenced me most to be 'student-friendly' is seeing my siblings and my cousins at home struggle with the current situation. I saw them accomplish a lot of activities or requirements. Some of my cousins come to our house just to share with our internet." Additionally, E2 mentioned that she got some data online: "The ones you read online such as people committing suicide or those who experience difficulties are rampant. Well, I took them all into consideration, and that's how I navigated my classes during the height of the COVID-19 pandemic." On another note, the number of course preparations affected some educators in a difficult way during the pandemic. Some responses included:

"E1: The more preparations you have, the more difficult it is."

"E2: Ahh, I think it did because the preparations are many especially that there are a lot of students too."

"E8: Even though I only have between 3 and 4 preparations during the pandemic, I feel like the loads were really heavy. It affected me in my migration in such a way that it gave me more difficult time to prepare for the modules as I was not used to this kind of orientation."

The above-mentioned responses are supported by the succeeding studies. The increase of teacher job duties, according to the research of Bartlett (2007), contributes to teacher overwork. The most prevalent source of stress is job overload, and the sole predictor of emotional fatigue and depersonalization (Zhang \& Zhu, 2007).

\subsection{Research Question 2}

In general, the award-winning educators conducted their classes through the use of preparation and implementation. The preparation commenced during the mid-term of the Academic Year: 
2019-2020, while the implementation took place in the first semester in the Academic Year: 2020-2021.

\subsubsection{Preparation}

Teachers are not completely prepared or properly educated to teach through Emergency Remote Teaching (ERT), and they face problems as a result of their lack of preparedness for a rapid change from traditional to online-based curriculum (Toquero \& Talidong, 2020). To mitigate this plight, the educators mentioned that the State University in which they are working has a Learning Management System (LMS) called Google Classroom. The university also conducted a university-wide orientation and training in the use of Google Classroom to help faculty members in their migration. E2 explicated how this move benefitted her.

"E2. The 5Es in the creation of modules were explained to us. It is good that they conducted those seminars. Then, we were given tips on how to conduct classes in Google Classroom. This information helped us especially on how to handle students online."

Unfortunately, not all the award-winning educators were able to attend the orientation and training due to valid reasons. E1, E4, E7, and E8 did not make it because they were newlyhired when the pandemic struck, and the orientation and training were conducted prior to their hiring in the university. This cannot be any more emphasized as many educators believe that instructors need additional training in using technology in the classroom, particularly how to use technology in mixed and online formats (Trust \& Whalen, 2020). To supplement their current knowledge on Google Classroom, one educator sought help from her kids: "E3: What I did was to experiment and to ask my two children to be my students while creating the class. And then, I did a trial and error." Other educators supplemented their know-how by seeking help from peers/colleagues:

\section{"E2: Peer sharing helped a lot."}

"E5: Ask your colleagues who know because it still helps. At least, you gain a little idea on how to do it."

\subsubsection{Implementation}

The award-winning educators implemented varied ways to conduct their classes during the COVID-19 pandemic through online and offline instructional methods, formative and summative assessments, and feedback which are exemplified in the table below.

Table 2.

Educators' Classroom Implementation

\begin{tabular}{|c|c|c|}
\hline Instructional Methods & Assessment & Feedback \\
\hline 1.Video lectures via & 1. Formative assessments such & 1. Individual feedback provided in Google \\
\hline PowerPoint Presentations & as self-assessment & Classroom and Facebook Messenger to call \\
\hline 2.Instructor-made videos & questionnaires, interviews, & the attention of students, to acknowledge \\
\hline 3. Voice recordings & guide questions, quotes and & students' submissions, to ensure the receipt \\
\hline 4.Google Forms & photo interpretations, puzzles, & of the materials, to point out errors, to \\
\hline 5.Google Meet & and surveys & provide comments, and \\
\hline 6.Zoom & 2. Summative assessments via & encouragement \\
\hline 7.PlagScan & Google Forms and videos & 2. Collective feedback solely provided \\
\hline 8.grammarly & & through Facebook Messenger to reiterate \\
\hline 9.Facebook Groups & & something on their work, to remind them \\
\hline 10. Facebook Messenger & & that requirements are submitted, to remind \\
\hline 11. Facebook Live & & them that requirements are not submitted, \\
\hline 12. YouTube & & and to remind them that requirements are \\
\hline 13. Text messages ( & & submitted on time \\
\hline 14. Phone calls (Offline) & & 3. Feedback from students during classes, \\
\hline 15. Printed Modules (Offline) & & $\begin{array}{l}\text { through Google Forms, and after sifting } \\
\text { comments on Facebook }\end{array}$ \\
\hline
\end{tabular}


For starters, the educators utilized Google Classroom in their implementation. But then, they incorporated various online tools to be flexible in the conduct of their classes which were only used in a limited way before the pandemic, according to the respondents of Tartavulea, Albu, Albu, Dieaconescu, and Petre (2020). The responses below show how the educators used the methods in their classes.

"E1: I usually use Fb Messenger because it is the most accessible to my students. I also make video lectures and Google Meet. For my students who cannot attend the synchronous class on Google Meet, I just upload the copy of the video lectures."

"E3: What I do is I give lectures through $\mathrm{Fb}$ live streaming which they can watch asynchronously. Those who can join me live can ask questions through the chat box. Of course, I also use email, group chats through Messenger, and text messages. I've really tried so hard studying how Google Classroom works, and how Zoom classes are done."

"E8: The instructional methods that I incorporate in the classroom are text messages, phone calls, Google Forms, online modules, YouTube videos, self-made videos, audio recordings, Facebook Pages, Facebook Messenger, and Google Meet in my research classes only. The rest of the courses are conducted asynchronously. I did not have any student who subscribed to printed modules, but I have my modules ready just in case."

Although majority of the methods used by the educators are found online whereby their use has increased in the midst of the pandemic, the educators still offered offline learning or printed modules as an option for students. For this reason, E1 pointed out that "It gives equal opportunities for my students to have access to the learning materials."

\subsubsection{Assessments}

The award-winning educators used both formative and summative assessments in the delivery of their lessons. Baht and Bhat (2019) defined formative assessment as a collection of formal and informal evaluation techniques used by instructors to adjust teaching and learning activities in order to improve student achievement. Summative assessment, however, is a number or letter grade score that is used for evaluation when there is little or no feedback beyond the accomplishment report (Glazer, 2014).

All of the educators stated that examinations were done through Google Forms, and summative assessments were mostly done via paper-and-pencil tests. E5, E7, and E8 mentioned that they also required their students to create videos as part of their summative assessments. One educator responded: "E7: For example, on painting, they can also do interpretation through videos or vlogging." On the other hand, formative assessments were done in varied ways such as self-assessment questionnaires, interviews, guide questions, quotes and photo interpretations, puzzles, and surveys. One educator explained: "E3: Yes, I use online quizzes, varied online quizzes, from objective type to essay to activities like maybe puzzles, answering of puzzles, interviewing, among others. We also do formative activities like interviews, surveys, and essays."

\subsubsection{Feedback}

The award-winning educators all provided a form of feedback to students during the COVID19 pandemic. Planar and Moya (2016) fairly concluded that giving students with useful feedback that they can utilize is crucial to supporting and improving their experience in higher education. This is done individually and collectively using various methods by the educators. The individual feedback was provided in Google Classroom and Facebook Messenger to accomplish the following:

to call the attention of students: "E3: I tell them who did not answer a specific item in the activity." 
to acknowledge students' submissions: "E5: Usually, my acknowledgment is a thumbs up. Then, they will also respond through a thumbs up."

to ensure the receipt of the materials: "E5: In general, I ask them if they receive them (materials $\}$ or if they can play the videos."

to point out errors: "E6: I get to message them individually especially for major errors."

to provide comments: "E2: I use PlagScan premium account and grammarly premium account courtesy of our library. That's one way to open other ways to give feedback and comments." and to provide encouragements: "E7: I make a note to appreciate what they did regardless of how it looks like. I say 'Keep up!' just to encourage them."

The collective feedback was solely provided through Facebook Messenger. The awardwinning educators did this:

to reiterate something on their work: "E8: I provide general feedback to common errors in students' submissions. In my Corporate English class, I point out what they did well and on what they need improvement."

to remind them that requirements are submitted: "E6: I also provide feedback for all once they submit their requirements."

to remind them that requirements are not submitted: "E3: If they did not submit the outputs, I remind them every now and then." and

to remind them that requirements are submitted on time: "E1: Sometimes, I give general comments when the class finished the requirements on time."

A commonality among all award-winning educators during the COVID-19 pandemic was asking feedback from students regarding their performance in conducting their classes. This in conjunction with the study of Husain and Khan (2016) which states that feedback from students is a useful technique for evaluating instructors resulting in faculty improvement. One way the educators did this was through asking feedback during their classes.

"E2: Whenever I conduct Google lectures, I ask them if I am fast or if they understand the lecture."

"E5: I ask the students if they received the video, whether they could play the video, or if they understood it (the video)."

Other educators asked students using Google Forms to rate and to give comments on their teaching.

"E1: I attach a Google Form where they could write or they could rate me."

"E4: I placed a Google Form in our Google Classroom. Then, I just asked for comments or suggestions. I added the things that they found difficult in learning the subject and the things that helped them understand."

"E8: After the distribution of the final grades, I sent them a Google Form to determine what they found effective or what they appreciated in my teaching, what I could improve on, and a rate from 1-5 how I performed in that given semester."

Finally, E2 found a unique approach of browsing Facebook to elicit students' feedback. After sifting the posts and comments of students on Facebook, she incorporated what was necessary in her classes.

"E2: What I do is that I read my students' posts on Facebook. I read comments like 'I wish the teacher would give a lecture', 'I hope it would not just be modules', or 'I hope five activities would not be due in just a week'. So, I get it from them, from their posts.”

\subsection{Research Question 3}

The award-winning educators identified several roadblocks that they encountered in the conduct of their classes during the COVID-19 pandemic; nevertheless, they enumerated ways on how they overcame them. The themes are synthesized in the table. 
Table 3.

Roadblocks and Solutions

\begin{tabular}{ll}
\hline \multicolumn{1}{c}{ Roadblocks } & \multicolumn{1}{c}{ Solutions } \\
\hline Internet connectivity & $\begin{array}{l}\text { Using self-learning packets/offline modules and multiple platforms } \\
\text { Staying professional in answering students, reaching out to them, and } \\
\text { Communication with students }\end{array}$ \\
$\begin{array}{l}\text { Using dialects or the language that students commonly understand } \\
\text { cameras during summative assessments, using grammarly and PlagScan } \\
\text { to detect plagiarism, and dividing students in groups }\end{array}$ \\
Quality of students' work & $\begin{array}{l}\text { Selecting the most essential learning competencies needed by students and } \\
\text { minimizing digital divide }\end{array}$ \\
Teaching laboratory courses & Sending comprehensive videos \\
Well-being of the educators & Setting a schedule to accomplish tasks \\
\hline
\end{tabular}

\subsubsection{Internet Connectivity}

Internet connectivity was the most common roadblock experienced and expressed by the educators. They added that this was the biggest roadblock experienced by students. Since they were in their respective provinces, internet connectivity became more problematic. In the Philippines, internet access continues to be a challenge (Azcarraga \& Peña, 2019). Salac and Kim (2016) added that the country's Internet infrastructure falls behind that of modern Asian developing countries, especially in terms of Internet connection, ranking 104th out of 160 countries in 2015. E1 clarified that: "E1: The major problem is on the availability of internet for our students and for us, teachers. In the case of the students especially those in the provinces who really do not have signals, it becomes even more burdensome."

These educators provided self-learning packets/ offline modules or used multiple platforms to overcome it.

"E1: One solution is the offline mode of delivery for those who have poor internet connectivity."

"E6: Well, I use more than one platform. Hopefully, I could address it (internet problem) using Facebook messenger, text messages, or emails."

\subsubsection{Communication with Students}

Some problems indicated by the award-winning educators regarding communication with students are students' forgetting their ethics, not replying to the educators, and the use of English in communication.

"E3: There were just a few who don't know their ethics when they communicate with me online. Since I'm a human being too, I'm sometimes irritated."

"E6: Not all are communicating with me. There are still a lot who are so silent that I have to reach out to them."

"E7: There are students who do not understand my instructions because they are written in English. As a result, they ask questions which are already found in the instructions."

Despite these, they enumerated solutions to the stated roadblock which are as follows: being professional in answering students, reaching out to them, and using dialects or the language that students commonly understand.

"E3: I simply embody professionalism and answer them the subtlest way possible."

"E6: There are some students who do not answer my messages and my text messages, so

I constantly reach out to them." 
"E7: Sometimes, I have to shift from English to Filipino or even in their local language even if it is an English course for them to understand the instructions better."

\subsubsection{Integrity of Students' Work}

Another problem cited by the award-winning educators had something to do with the integrity of students in turning their requirements in. They were concerned about cheating in the forms of plagiarism and students' having identical answers as evidenced below.

"E1: In student assessment, one of the problems is the difficulty of controlling their honesty. Since we are not present, we may expect that some of them would be cheating."

"E4: Since I have essay questions, I believe that everyone is smart, but I sometimes question how grammatically perfect their requirements are."

"E6: I see a lot of submissions that are exactly the same especially last year."

The educators overcame this roadblock via the use of extensions on Google Classroom, letting students open their cameras during summative assessments, using grammarly and PlagScan to detect plagiarism, and dividing students in groups.

"E1: One of the means maybe to minimize, but not to prevent cheating, is the use of applications like AutoProctor installed in the Google Form to track the students during the assessment. Its camera sees if the student is focused."

"E4: Since Grammarly and PlagScan detected what and how much they plagiarized, I gave them certain deductions."

"E6: Since cheating is a problem, I decided to divide them (students) by pairs or by threes, so, so, at least, they will discuss their answers before submitting."

\subsubsection{Quality of Students' Work}

In terms of quality of work, rushed work due to working students and the challenge of digital divide were a roadblock according to the award-winning educators.

"E1: Compared to face-to-face interaction, it seems that the quality of what they are submitting now is lower, maybe because they also do a lot at the same time, and some of them are working. As a result, they see the requirements late, so they just do them quickly."

"E6: This is where the digital divide becomes obvious. Those with internet connectivity would have good submissions especially with infographics or those things that use resources online, which students in the provinces cannot do so."

The educators responded to these by selecting the most essential learning competencies needed by students and minimizing digital divide.

"E1: In this case, I had to select only the most necessary competencies in the curriculum so that the students will not feel overloaded."

"E6: I know the struggle, so I do not give more credit to those who use online resources because it becomes a battle of resources. What is important to me is their ability to synthesize information not necessarily how aesthetically pleasing their works are."

\subsubsection{Teaching Laboratory Courses}

Another roadblock identified by E1 was teaching laboratory courses: "E1: The most challenging part is really teaching laboratory subjects. Students cannot do the practicals or the skills part of the laboratory." She overcame this situation by sending comprehensive videos: "E1: So, I just send them comprehensive, step-by-step videos." 


\subsubsection{Well-being of the Educators}

Finally, E7 explained that maintaining her wellbeing became a roadblock: "E7: More time is spent for checking late submissions that's why it has an effect on my wellbeing." Nonetheless, she overcame this by setting a schedule to accomplish her tasks: "E7: As much as possible, I really set deadlines for myself, so I do not have to extend."

\section{Conclusion}

The primary purpose of this study was to spotlight the pedagogical practices and teaching experiences of award-winning educators in a State University in the Philippines during the COVID-19 pandemic. One finding showed that years in service and educational attainments were helpful factors in the educators' migration from face-to-face to distance education which means that educators in general are encouraged to continue reflecting on their teaching experience in these trying times and continue in their advanced degrees in their respective fields of specialization. However, the number of course preparations per semester made teaching in the pandemic more difficult. This implies that educators could have more focus in preparing their classes which are tailor-fit in distance education if their number of preparations is lowered. Another finding showed that the award-winning educators conducted their classes by means of preparation and implementation. These are procedures that other State University educators and teachers in general may adopt or modify in the Philippines. Moreover, a recurring theme during the educators' interview was the emphasis on the use of empathy in teaching. They said that educators have to be kind, need to focus on the students, do everything with love, be more considerate, among others. In support, this can aid in the creation of innovative solutions to pedagogical issues where the emphasis is on having a compassionate and empathetic approach to teaching (Baran \& Alzoubi, 2020; Bozkurt \& Sharma, 2021). This may become a reminder to all educators to put themselves in the shoes of their students while designing their classes. At last, the educators specified roadblocks that they encountered during the first semester of the Academic Year, 2020-2021, and how they overcame them. This may provide an avenue for teachers to reflect on the same problems or implement the same solutions wherever and whenever they deem necessary.

The study has several limitations, though. First, the research was only limited to the pedagogical practices and teaching experiences of award-winning educators in one State University in the Philippines. Second, generalizing the findings may not be possible due to the nature of its design. Finally, only eight among ten of the awardees participated. In the future, a comparison can be drawn from other educators in other State Universities and colleges in the Philippines. Other researchers could also lean on the perceptions of students regarding the best practices employed by their teachers during the pandemic.

\section{Acknowledgments}

The researcher would like to express his sincerest gratitude to the award-winning educators in the study and to Dr. Manilyn R. Cacanindin for her unwavering support.

\section{References}

Alawamleh, M., Al-Twait, L., \& Al-Saht, G. (2020). The effect of online learning on communication between instructors and students during the Covid-19 pandemic. Asian Education and Development Studies. https://doi.org/10.1108/AEDS-06-2020-0131

Arain, S., \& Munshi, P. (2019). Issues of distance education tutors in Pakistan: A study on print-based distance education. International Journal of Experiential Learning \& Case Studies, 4 (2), 356-367. DOI:10.22555/ijelcs.v4i2.2568 
Azcarraga, A., \& Peña, P.J. (2019). Technology and Automation as sources of $21^{\text {st }}$ century firm productivity: The economics of slow internet connectivity in the Philippines. DLSU Research Congress 2019. https:/www.dlsu.edu.ph/wp-content/uploads/pdf/conferences/ research-congress-proceedings/2019/see-II-030.pdf

Baht, B.A., \& Bhat, G.J. (2019). Formative and summative evaluation techniques for improvement of learning process. European Journal of Business \& Social Sciences, 7 (5), 776-785. https://www.researchgate.net/profile/Bilal-Bhat-6/publication/333633265 Formative_and_Summative_Evaluation_Techniques_for_Improvement_of_Learning_Proc ess/links/5e6b7e48a6fdccf321d9926e/Formative-and-Summative-Evaluation-Techniquesfor-Improvement-of-Learning-Process.pdf

Baran, E., \& Al Zoubi, D. (2020). Human-centered design as a frame for transition to remote teaching during the COVID-19 pandemic. Journal of Technology and Teacher Education, 28(2), 365-372. https://www.learntechlib.org/primary/p/216077/

Bartlett, L. (2004). Expanding teacher work roles: A resource for retention or a recipe for overwork. Journal of Education Policy, 19 (5), 565-582. https://doi.org/10.1080/026809 3042000269144

Bertiz, y., \& Kocaman Karoğlu, A. (2020). Distance education students' cognitive flexibility levels and distance education motivations. International Journal of Research in Education and Sciences, 6 (4), 638-648. DOI:10.46328/ijres.v6i4.1022

Bozkurt, A., \& Sharma, R. C. (2021). On the verge of a new renaissance: Care and empathy oriented, human-centered pandemic pedagogy. Asian Journal of Distance Education, 16 (1), 1-7. http://www.asianjde.com/ojs/index.php/AsianJDE/article/view/576

Cascayan, W., Delos Reyes, N., Miguel, S., Langbis, M., Estrada, M., Molina, B., Sanchez, G., Tolentino, L., Escalona, J., \& Paraggua, C. (2021). Flexible learning among criminology students of Data Center College of the Philippines. International Journal of Innovative Science and Research Technology, 6 (4), 977-996. https://www.ijisrt.com/assets/upload/ files/IJISRT21APR427.pdf

CHED Memorandum Order No. 4, s. 2020. Guidelines on the implementation of flexible learning. https://ched.gov.ph/wp-content/uploads/CMO-No.-4-s.-2020-Guidelines-on-theImplementation-of-Flexible-Learning.pdf

Creswell, J., \& Poth, C. (2018). Qualitative inquiry and research design: Choosing among five approaches (eds). Sage Publications Inc.

Cunningham, D. (2021). A case study of teachers' experiences of blended teaching and learning. Journal of Online Learning Research, 7 (1), 57-83. Waynesville, NC USA: Association for the Advancement of Computing in Education (AACE). https://www.learntechlib.org/primary/p/213808/

Daniel, S.J. (2020). Education and the COVID-19 pandemic. Prospects, 49, 91-96. https://doi.org/10.1007/s11125-020-09464-3

Dhawan, S. (2020). Online learning: A panacea in the time of the COVID-19 crisis. Journal of Educational Technology System, 49 (1), 5-22. DOI: 10.1177/0047239520934018

Gayon, R., \& Tan, D. (2021). Experiences of higher education institution (HEI) teachers in the implementation of flexible learning. Science International 33 (1), 47-52. https://www. Researchgate.Net/Publication/350090182_Experiences_Of_Higher_Education_Institution _Hei_Teachers_In_The_Implementation_Of_Flexible_Learning 
George, M. (2020). Effective teaching and examination strategies for undergraduate learning during COVID-19 school restrictions. Journal of Educational Technology Systems, 49 (1), 23-48. DOI: $10.1177 / 0047239520934017$

Glazer, N. (2014). Formative plus summative assessment in large undergraduate courses: Why both? International Journal of Teaching and Learning in Higher Education, 26 (2), 276-286. https://files.eric.ed.gov/fulltext/EJ1060846.pdf

Gökbulut, B. (2020). Distance education students' opinions on distance education. Enriching Teaching and Learning Environments with Contemporary Technologies (pp.138-152). https://www.researchgate.net/publication/339118173_Distance_Education_Students\%27_ Opinions_on_Distance_Education

Harrison, J. (2013). 4 good reasons you should pursue an advanced degree. Black Enterprise. https://www.blackenterprise.com/4-good-reasons-to-pursue-graduate-school-advanceddegree/

Husain M., \& Khan, S. (2016). Students' feedback: An effective tool in teachers' evaluation system. International Journal of Applied \& Basic Medical Research, 6 (3), 178-181. DOI: 10.4103/2229-516X.186969

Irvine, J. (2019). Relationship between teaching experiences and teacher effectiveness: Implications for policy decisions. Journal of Instructional Pedagogies, 22, 1-19. https://files.eric.ed.gov/fulltext/EJ1216895.pdf

Jose Sa, M., \& Serpa, S. (2020). The COVID-19 pandemic as an opportunity to foster the sustainable development of teaching in higher education. Sustainability, 12, 8525. doi:10.3390/su12208525

Kallio, H., Pietila, A., Johnson, M., \& Kangasniemi, M. (2016). Systematic methodological review: Developing a framework for a qualitative semi-structured interview guide. Journal of Advanced Nursing, 72 (12), 2954-2965. http://dx.doi.org/10.1111/jan.13031

Kapur, R. (2019). Distance education. https://www.researchgate.net/publication/335991388 _Distance_Education

Klett, L. (2018). Teacher shortage crisis: Why an advanced degree in education makes a big difference. Liberty University. https://www.christianpost.com/sponsored/teacher-shortagecrisis-why-an-advanced-degree-in-education-makes-a-big-difference.html

Morgan, H. (2020). Best practices for implementing remote learning during a pandemic. The Clearing House: A Journal of Educational Strategies, 93 (3), 134-140. https://doi.org/10. 1080/00098655.2020.1751480

Morris, A. (2015). A practical introduction to in-depth interviewing. SAGE Publications Inc.

Sundler, A., Lindberg, E., Nilsson, C., \& Palmer, L. (2019). Qualitative thematic analysis based on descriptive phenomenology. Nursing Open, 6, 733-739. DOI: 10.1002/nop2.275

Nikolaros, J. (2019). High school teachers with significant teaching experience support the effectiveness of direct instructional strategies. Contemporary Issues in Education Research, 7 (3), 189-194. https://eric.ed.gov/?q=experience+and+teacher+effectiveness\&id=EJ1073245

Panev, I. (2021). Online teaching in higher education during COVID-19 pandemic. World Journal of Educational Research, 8 (2), 96-102. http://dx.doi.org/10.22158/wjer.v8n2p96

Planar, D. \& Moya, S. (2016). The effectiveness of instructor personalized and formative feedback provided by instructor in an online setting: some unresolved issues. The Electronic Journal of e-Learning, 14 (3), 196-203. https://files.eric.ed.gov/fulltext/EJ1107130.pdf 
Rapanta, C., Botturi, L., Goodyear, P., Guradia, L., \& Koole, M. (2020). Online university teaching during and after the Covid-19 crisis: Refocusing teacher presence and learning activity. Postdigital Science and Education, 2, 923-945. https://doi.org/10.1007/s42438020-00155-y

Rasmitadila, Aliyyah, R., Rachmadtullah, R., Samsudin, A., Syaodih, E., Nurtanto, M., \& Tambunan, A. (2020). The perceptions of primary school teachers of online learning during the COVID-19 pandemic period: A case study in Indonesia. Journal of Ethnic and Cultural Studies, 7 (2), 90-109. http://dx.doi.org/10.29333/ejecs/388

Rice, J. (2013). Learning from experience? Evidence on the impact and distribution of teacher experience and the implications for teacher policy. Education Finance and Policy, 8 (3), 332-348. https://doi.org/10.1162/EDFP_a_00099

Salac, R. A., \& Kim, Y. S. (2016). A study on the internet connectivity in the Philippines. Asia Pacific of Journal Review 1 (1), 67-88. https://doi.org/10.20522/APJBR.2016.1.1.67

Sayk1l1, A. (2018). Distance education: Definitions, generations, key concepts and future directions. International Journal of Contemporary Educational Research, 5 (1), 2-17. https://files.eric.ed.gov/fulltext/EJ1207516.pdf

Sharonova, S., \& Avdeeva, E. (2020). Comparison of distance education and smart education. Revista Tempos e Espaços em Educação, 13 (32), 1-15. DOI:10.20952/revtee.v13i32.14689

Shenoy, V., Mehndra, S., \& Vijay, N. (2020). COVID 19 - lockdown: Technology adaption, teaching, learning, students' engagement and faculty experience. Mukt Shabd Journal, 9 (14), 698-702. https://www.researchgate.net/publication/340609688

Short, C.R., Graham, C.R., \& Sabey, E. (2021). K-12 blended teaching skills and abilities: An analysis of blended teaching artifacts. Journal of Online Learning Research, 7(1), 5-33. Waynesville, NC USA: Association for the Advancement of Computing in Education (AACE). https://www.learntechlib.org/primary/p/217689/

Spoel, I., Noroozi, O., Schuurink, E., \& Ginkel, S. (2020). Teachers' online teaching expectations and experiences during the Covid19-pandemic in the Netherlands. European Journal of Teacher Education. DOI: 10.1080/02619768.2020.1821185

Stevens, M. (2020). Expertise, complexity, and self-regulated engagement: Lessons from teacher reflection in a blended learning environment. Journal of Online Learning Research, 6(3), 177-200. Waynesville, NC USA: Association for the Advancement of Computing in Education (AACE). https://www.learntechlib.org/primary/p/216912/

Stanistreet, P., Elfert, M., \& Atchoarena, D. (2021a). Education in the age of COVID-19: Understanding the consequences. International Review of Education, 66, 627-63. https://doi.org/10.1007/s11159-021-09904-y

Stanistreet, P., Elfert, M., \& Atchoarena, D. (2021b). Education in the age of COVID-19: Implications for the future. International Review of Education, 67, 1-8. https://doi.org/ $10.1007 / \mathrm{s} 11159-020-09880-9$

Tadeo, C. (2021). Online distance learning: A teaching strategy on improving students' performance in social studies in the new normal. European Journal of Humanities and Educational Advancements, 2 (5), 46-50. https://doi.org/10.17605/OSF.IO/CET2F

Tartavulea, C., Albu, C., Albu, N., Dieaconescu, R., and Petre, S. (2020). Online teaching and the effectiveness of the educational process in the wake of the Covid-19 pandemic. Amfiteatru Economic, 22 (55), 920-936. DOI: 10.24818/EA/2020/55/920 
Toquero, C., \& Talidong, K. (2020). Webinar technology: Developing teacher training programs for emergency remote teaching amid COVID-19. Interdisciplinary Journal of Virtual Learning in Medical Science, 11 (3), 200-2013. DOI: 10.30476/IJVLMS. 2020.86889.1044

Trovela, E. (2021). Perceptions of parents and learners to modular distance learning as a contemporary teaching strategy. International Journal of Research and Development, 6 (6), 283-296. https://doi.org/10.36713/epra7330

Trust, T., \& Whalen, J. (2020). Should teachers be trained in emergency remote teaching? Lessons learned from the COVID-19 pandemic. Journal of Technology and Teacher Education, 28 (2), 189-199. https://www.learntechlib.org/primary/p/215995/.

Williams, T., Mcintosh, R., \& Russell, W. (2021). Equity in distance education during COVID19. Research in Social Sciences and Technology, 6 (1), 1-24. DOI:10.46303/ressat.2021.1

Zhang, Q., \& Zhu, W. (2007). Teacher stress, burnout, and social support in Chinese secondary education. Human Communication, 10 (4), 487-496. http://citeseerx.ist.psu.edu/viewdoc/ download?doi $=10.1 .1 .621 .1895 \&$ rep $=$ rep1\&type $=$ pdf

Zamora-Antuñano, M., Rodriguez, J., Segura, L., Cruz, M., Altamirano-Corro, J., ParedesGarcia, W., \& Resendiz, H. (2021). Analysis of emergency remote education in COVID-19 crisis focused on the perception of the teachers. Sustainability, 13 (7), 3820. DOI: $10.3390 /$ su13073820 